\title{
Right paraduodenal hernia
}

\section{P A Scheepers, $M B C h B$}

Department of Diagnostic Radiology, University of Limpopo, Medunsa Campus

A 30-year-old man was referred from a peripheral hospital with a 6-day history of abdominal pain and vomiting. He had been constipated for the previous 3 weeks. He was acutely ill and de hydrated. His pulse rate was $102 / \mathrm{min}$, blood pressure $(\mathrm{BP}) 115 / 65 \mathrm{mmHg}$, respiratory rate 20/min and temperature $37.9^{\circ} \mathrm{C}$.

Abdominal examination revealed a distended stomach with a succussion splash. There was no rebound tenderness and rectal examination revealed stools in the rectum. A provisional diagnosis of a gastric outlet obstruction was made and a nasogastric tube was inserted draining green gastric contents.

An abdominal X-ray was rather nonspecific showing a single dilated loop of small bowel with some fluid levels in the right upper quadrant and stools and air in the rectum.

Serum electrolytes and full blood count (FBC) were compatible with dehydration and vomiting, with urea $30.2 \mathrm{mmol} / \mathrm{l}$, potassium $2.5 \mathrm{mmol} / \mathrm{l}$, and sodium $130 \mathrm{mmol} / \mathrm{l}$. The white cell count was $11.5 \times 10^{9} / 1$.

Endoscopic examination showed a normal oesophagus and stomach

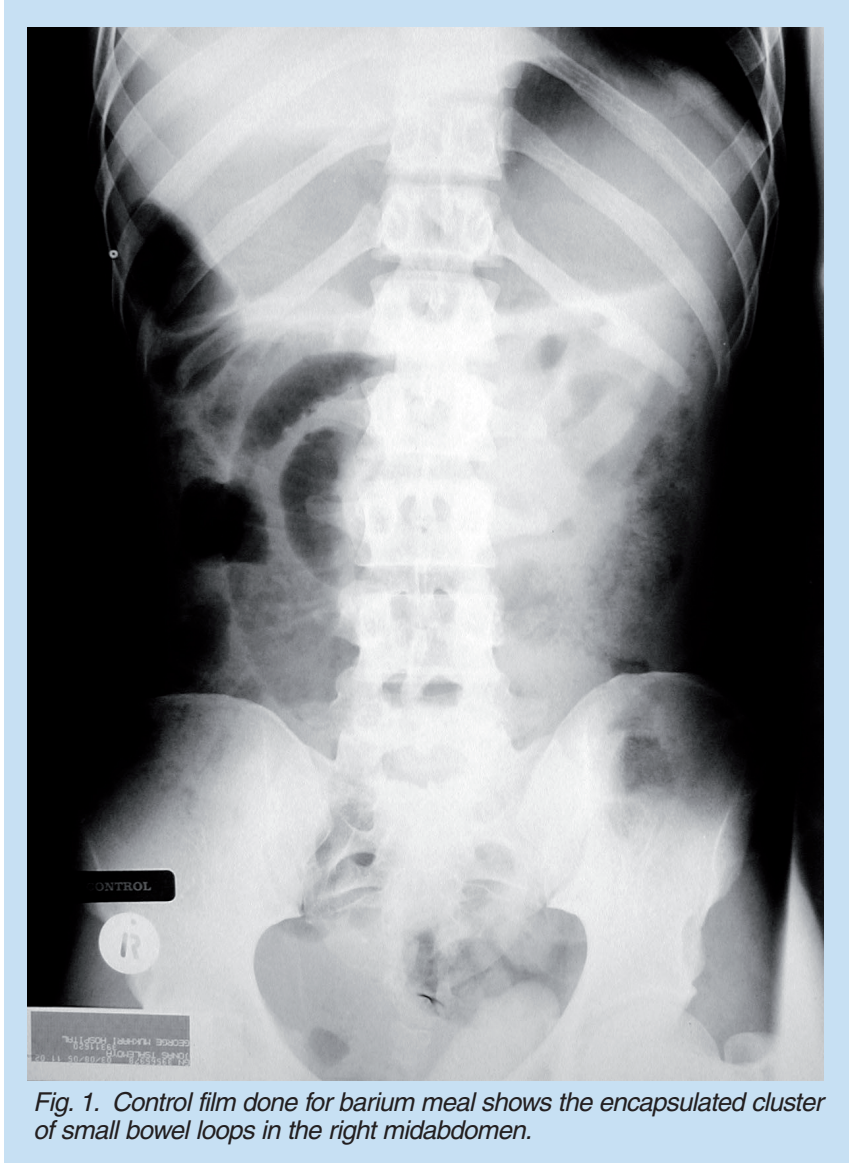

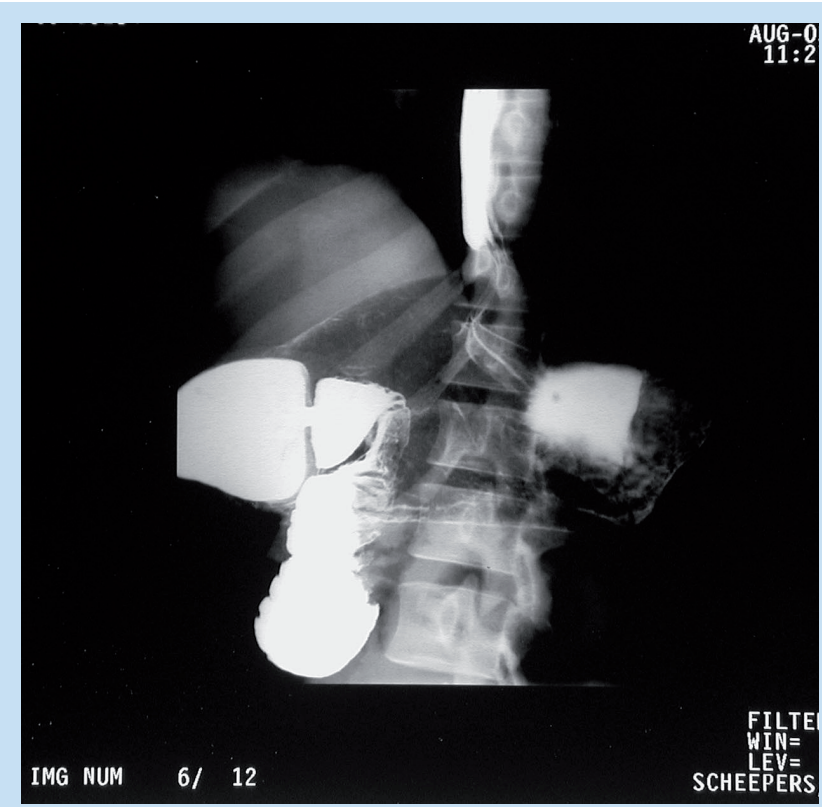

Fig. 2. Barium meal showing dilated stomach with normal-appearing antrum and duodenal cap. The descending part of the duodenum is dilated.

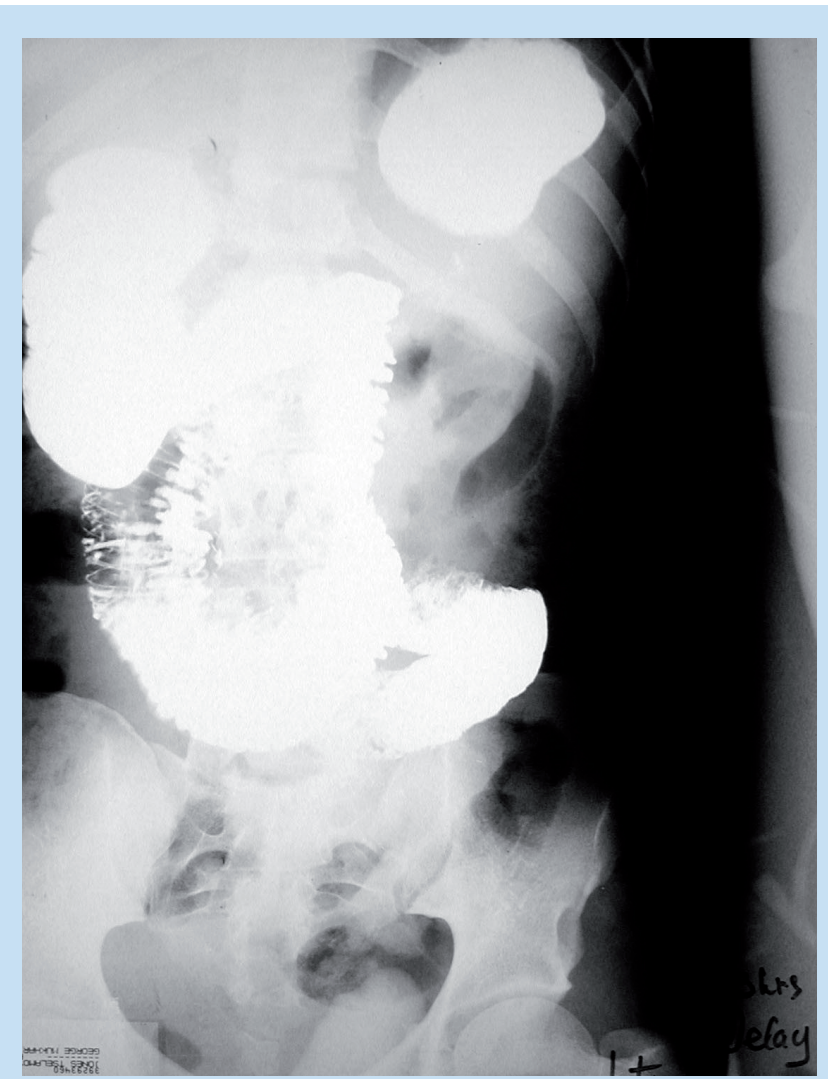

Fig. 3. A 45-minute delay film shows the encapsulated cluster of jejenum loops in the right midabdomen in the fossa of Waldeyer. 


\section{CASE REPORT}

filled with green fluid. The pylorus and duodenum could not be identified.

The patient was subsequently referred for barium meal, with the provisional diagnosis of a gastric outlet obstruction. A control film done (Fig. 1) before the procedure showed a cluster of small bowel loops in the right mid abdomen. Barium meal revealed a normal oesophagus, stomach and duodenal cap. The transition of barium through the duodenum was slow and it showed dilatation of the first and second parts (Fig. 2). A cluster of jejunal loops was identified on 45-minute delay film, extending inferiorly and to the right of the 3rd and 4th part of the duodenum (Fig. 3).

These findings were suggestive of a right-sided paraduodenal hernia and this was confirmed at laparotomy. A gangrenous loop of encapsulated jejunum was resected and primary anastomosis was performed. The hernia opening was closed. The patient's postoperative course of the patient was without complications.

\section{Discussion}

Paraduodenal hernias fall under the group of internal hernias. An internal hernia is classified as the protrusion of a viscus through a peritoneal or mesenteric aperture, resulting in its encapsulation in another compartment within the confines of the peritoneal cavity. Internal hernias are rare, although according to recent reports ${ }^{1}$ they have become increasingly common. This might be attributed to the increased radiological diagnoses.

CT has become the method of choice in diagnosing any internal hernia, but as in this case, it can also be diagnosed on plain film and barium follow-through. Due to the fact that these hernias can reduce spontaneously preoperatively, and because all the peritoneal spaces are not always routinely examined intraoperatively, they can go undiagnosed during open surgery. ${ }^{1}$

In 1857 when Treitz described the peritoneal fold in the paraduodenal area he attributed paraduodenal hernias to the herniation of small bowel in the duodenojejunal fossa. ${ }^{2}$ In 1923, however, Andrews declared the term 'paraduodenal hernia' a misnomer. According to him, and generally accepted today, paraduodenal hernia is due to incomplete rotation of the midgut and is congenital in origin. ${ }^{2}$

When the fetus is 6 weeks old the midgut herniates into the umbilical cord. It then rotates $90^{\circ}$ while in the umbilical cord, $90^{\circ}$ on its way back into the abdomen, and a final $90^{\circ}$ within the abdomen to rotate a full $270^{\circ}$ counterclockwise around the superior mesenteric artery. If the pre-arterial segment rotates but the postarterial segment fails to rotate the small bowel is entrapped in the right mesocolon, and right paraduodenal hernia results. ${ }^{3}$

Internal hernias are rare, having an autopsy incidence of $0.2-0.9 \%$. Paraduodenal hernias account for more than $50 \%$ of these hernias. Right paraduodenal hernias account for only $25 \%$ of paraduodenal hernias and left-sided paraduodenal hernias for the rest.

A right-sided paraduodenal hernia is also called mesentericoparietal or congenital mesocolic hernia. ${ }^{3}$ Anatomically there are a number of paraduodenal fossae. The most important ones are the left paraduodenal fossa or fossa of Landzert and the right paraduodenal fossa or the fossa of Waldeyer.

The fossa of Landzert is to the left of the fourth part of the duodenum and extends behind the descending mesocolon, with the opening being just inferior to the duodenojejunal junction and bound anteriorly by the inferior mesenteric vein and the ascending left colic artery (Fig. 4a).

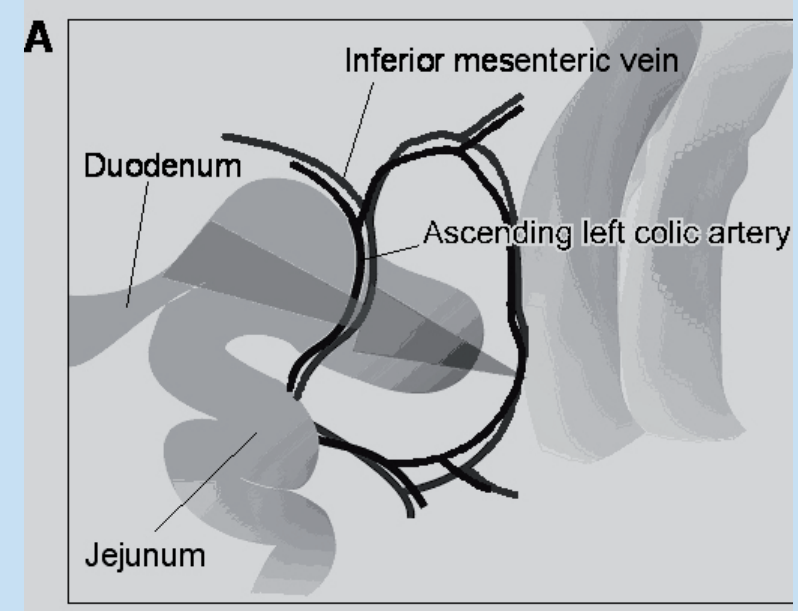

Fig. 4a. Schematic illustration demonstrating a left paraduodenal hernia behind the ascending left colic artery into the fossa of Landzert.

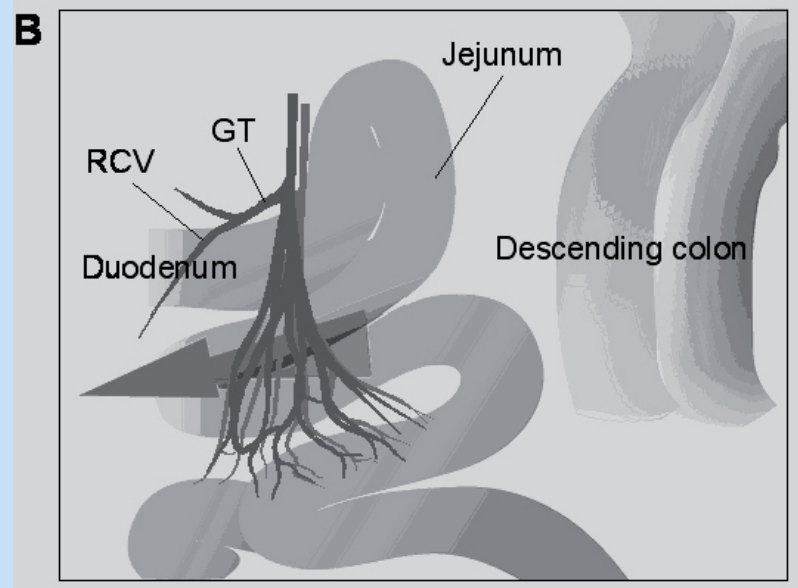

Fig. 4b. Schematic illustration demonstrating a right paraduodenal hernia into the fossa of Waldeyer behind the branches of the superior mesenteric artery and vein.

It is very important to recognise the inferior mesenteric vein where it joins the splenic vein or the superior mesenteric vein as this marks the duodenojejunal flexure. The inferior mesenteric vein and the left ascending colic artery displaced anteriorly by a cluster of jejunal bowel loops is the most important sign on CT of left paraduodenal hernia. ${ }^{3-5}$ These borders are also important surgically, as the inferior border of the hernia opening is the safest place to incise to widen the neck and allow reduction without risk of damage to vital structures. ${ }^{3}$

The fossa of Waldeyer extends inferior to the third and fourth part 


\section{CASE REPORT}

of the duodenum bounded anteriorly by the superior mesenteric artery and vein or the ileocolic artery and vein and posteriorly by the posterior abdominal wall (Fig. 4b). ${ }^{4-6}$ As with the fossa of Waldeyer, this leaves the inferior border of the hernia as the safest place for incision to widen the neck of the hernia opening. ${ }^{3}$

\section{Conclusion}

Paraduodenal hernia remains an elusive diagnosis. A solid understanding of the paraduodenal folds and fossae and the embryological development thereof is important to make the diagnosis. It is important for both surgeons and radiologists to be well aware of this condition, especially in the patient with chronic recurrent abdominal pain.

As seen in this case, the plain film of the abdomen can already be suggestive of paraduodenal hernia and the barium follow-through can be almost diagnostic. CT has become the gold standard for the diagnosis of any internal hernia.

Blachar A, Federle MP. Internal hernia: an increasingly common cause of small bowel obstruction. Semin Ultrasound CT MRI 2002; 23:174-183.

2. Shinohara T, Okugawa $\mathrm{K}$, Furuta C. Volvulus of the small intestine caused by right paraduodenal hernia: a case report. J Pediatr Surg 2004; 39:e8-e9.

3. Manji R, Warnock GL. Left paraduodenal hernia: an unusual cause of small bowel obstruction. Can J Surg 2001; 46:455-456.

4. Okino $\mathrm{Y}$, Kiyosue $\mathrm{H}$, Mori H, et al. Root of small bowel mesentery: correlative anatomy and CT features of pathological conditions. Radiographics 2001; 21:1475-1490.

5. Peltier J, Le Gars D, Page C, Yzet T, Laude M. The duodenal fossae: antomic study and clinical correlations. Surg Radiol Anat 2005; 27:303-307.

6. Papaziogas B, Souparis A, Makris J, Alexandrakis A, Papziogas T. Surgical images: Soft tissue. Right paraduodenal hernia. Can J Surg 2004; 47:195-196.

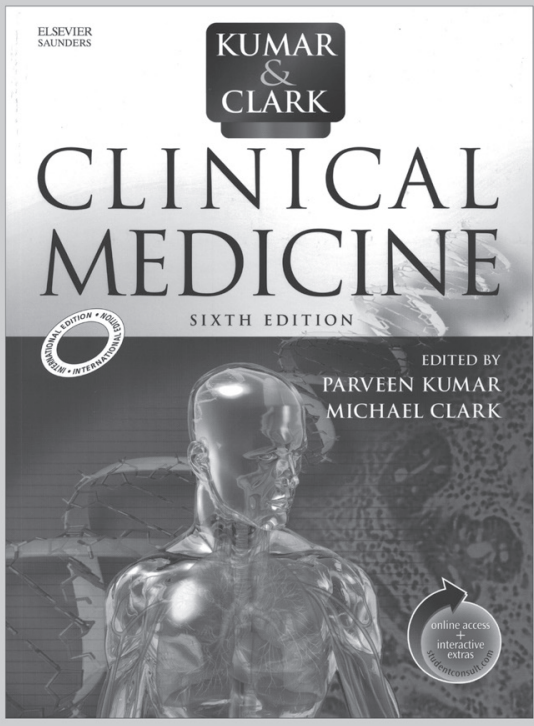

PRICE: R380.00

SAMA MEMBERS: R360.00

TO ORDER CONTACT:-

South African Medical Association

Health \& Medical Publishing Group

1-2 Lonsdale Building, Gardener Way,

Pinelands, 7405

Tel: (021) 530-6520/27

Fax: (021) 531-4126/3539

email: carmena@hmpg.co.za 